\title{
A Study on the Flocculation and Sedimentation of Iron Tailings Slurry Based on the Regulating Behavior of $\mathrm{Fe}^{3+}$
}

\author{
Tao Yue ${ }^{1,2}$, Xiqing Wu ${ }^{1,2, *}$, Xiao Chen ${ }^{1,2}$ and Tianyu Liu ${ }^{1,2}$ \\ 1 School of Minerals Processing and Bioengineering, Central South University, Changsha 410083, China; \\ wind383813056@csu.edu.cn (T.Y.); 165611070@csu.edu.cn (X.C.); 155611068@csu.edu.cn (T.L.) \\ 2 Key Laboratory of Hunan Province for Clean and Efficient Utilization of Strategic Calcium-Containing \\ Mineral Resources, Central South University, Changsha 410083, China \\ * Correspondence: xiqingwu@hotmail.com; Tel.: +86-130-3679-5285
}

Received: 31 August 2018; Accepted: 19 September 2018; Published: 21 September 2018

\begin{abstract}
Based on the regulating behavior of $\mathrm{Fe}^{3+}$, flocculation and sedimentation tests of iron tailings slurry flocculated using $2 \mathrm{mg} / \mathrm{L}$ anionic polyacrylamide (APAM) were studied, including the tests of $\mathrm{Fe}^{3+}$ dosage, regulating time, and $\mathrm{pH}$. Flocculation-sedimentation tests showed that: a recommended addition of $56 \mathrm{mg} / \mathrm{L} \mathrm{Fe}^{3+}$ produced a surprisingly bad flocculation effect; sedimentation ability decreased with the increase of regulating time, however, the regulating ability during the first 1 min was low; $\mathrm{Fe}^{3+}$ displayed a high regulating effect at $\mathrm{pH}$ 6-7, and then decreased with the increase of slurry $\mathrm{pH}$. Size analysis demonstrated that the regulating ability of $\mathrm{Fe}^{3+}$ was related to the change of floc size, which increased with the decrease of size. Zeta potential analysis and calculation showed that small concentrations of $\mathrm{Fe}^{3+}$ and certain hydroxyl complex ions (such as $\mathrm{Fe}(\mathrm{OH})^{2+}$ and $\mathrm{Fe}(\mathrm{OH})_{2}{ }^{+}$) adsorbed onto the APAM molecular chains, resulting in a decreased charge density of the APAM molecules, and this electrostatic adsorption was able to make the polymer curl more easily. Fourier Transform Infrared Spectroscopic (FTIR) indicated the APAM on the hematite was slightly degraded into a monomer-like short-chain polymer while adding certain concentration of $\mathrm{Fe}^{3+}$. Scanning Electron Microscope (SEM) imaging showed that the network structure of APAM molecules treated by $\mathrm{Fe}^{3+}$ collapsed, and the APAM adsorption amount on hematite was significantly reduced. Therefore, the effect of $\mathrm{Fe}^{3+}$ on the APAM could be recommended as a new method for desorption and degradation of the APAM contained in the tailings slurry or flocs.
\end{abstract}

Keywords: iron ion; desorption; degradation; polyacrylamide; flocculation-sedimentation; tailings

\section{Introduction}

Polyacrylamide (PAM) and derivative products are well-known flocculants widely applied in various fields, such as wastewater treatment [1,2], fine sedimentation [3,4], and agglomeration flotation [5] in mineral processing. There are three main types of PAM: anionic, cationic, and nonionic, and amongst them, the anionic PAM (APAM) usually exhibits a strong flocculating effect and has been used effectively for the flocculation-sedimentation process of tailings slurry $[4,6]$. The APAM polymer usually contains a large number of polar groups such as acyl and carboxyl groups, resulting in a high adaptability and strong adsorption capacity at alkaline $\mathrm{pH}$. APAM adsorbs well onto suspended particles in solution to form flocs, leading to an increased settling rate [4] for fine particles and producing good performance for fine flotation $[7,8]$.

As a water-soluble synthetic organic polymer, PAM is able to produce large flocs for water treatment or flotation by hydrogen bonding adsorption, chemisorption, and bridging adsorption [7]. However, PAM usually takes a long time to degrade naturally in the water system $[9,10]$, and sometimes 
a large addition of PAM could lead to an adverse effect on the following flotation separations of the target minerals [11] due to agglomerates containing many gangue particles. Chang [12] reported that a large concentration of 10-15 mg/L APAM used for the bauxite tailings sedimentation produced bad flotation selectivity in the following flotation process when the wastewater after the flocculation is recycled in the flotation.

In order to improve the flotation performance for using PAM as flocculants and reduce the adverse effect of residual PAM in the recycle wastewater, dispersants [12,13] could be applied in the slurry after flocculation, such as sodium hexametaphosphate $\left(\mathrm{NaPO}_{3}\right)_{6}$, and water glass, among others. Dispersants can produce a high degree of dispersion for fine suspension; however, it does not help affect the PAM molecular structure and its adsorption on particles. Therefore, methods for the PAM degradation on the particles can be proposed, such as mechanical degradation by stirring or ultrasonic degradation [14], biodegradation [15], thermal degradation [16,17], photocatalytic degradation [18-20], and oxidative degradation [21,22], etc. Among them, the oxidative degradation is a universal and practical method using oxidizing agents, such as $\mathrm{O}_{2}$, Fenton agent, $\mathrm{KMnO}_{4}$, and some metal ions, producing reactive free radicals during redox reactions and then leading to linked oxidation reactions for degradation [23].

Due to the presence of polar groups in the molecular chains, there might be electrostatic attraction and a cross-linked reaction between PAM and metal ions (especially including those high valence metal ions) [24-27]. Furthermore, the interaction between them could decrease the charge density on the APAM molecules, and then make the APAM molecular chains curl greatly and release "bound water" $[28,29]$. Studies [26,28] revealed that the PAM viscosity can be affected by metal ions via the electrostatic adsorption between metal ions and polar groups of PAM molecules, and the order of the interaction capacity using $10 \mathrm{mg} / \mathrm{L}$ metal ions was: $\mathrm{Fe}^{2+}>\mathrm{Mg}^{2+}>\mathrm{Ca}^{2+}>\mathrm{Na}^{2+} \approx \mathrm{K}^{+}$. These also suggested that high valence metal ions could produce stronger electrostatic interaction due to their positive charges, such as $\mathrm{Al}^{3+}$ and $\mathrm{Fe}^{3+}$, among others. Liu [30] found that the APAM adsorption amount on the magnetic seeds recycled from wastewater was reduced after adding metal ions of $\mathrm{Fe}^{2+}, \mathrm{Ca}^{2+}, \mathrm{Mg}^{2+}, \mathrm{K}^{+}$, and $\mathrm{Na}^{+}$. The study also claimed that the zeta potentials were increased via the adsorption of these metal ions on the magnetic seeds and the APAM polymer on the magnetic seeds was degraded into the water.

In this study, effects of the $\mathrm{Fe}^{3+}$ on the flocculation-sedimentation tests of iron tailings slurry flocculated using $2 \mathrm{mg} / \mathrm{L}$ APAM were investigated. The regulating behavior of $\mathrm{Fe}^{3+}$ on the slurry was characterized in terms of the decreased settling ability and the factual damage to the flocs' size in the presence of different concentration, regulating time, and pulp $\mathrm{pH}$. Then the regulating mechanisms were explored by flocs' size analysis, zeta potential study, FTIR, and SEM analysis.

\section{Materials and Methods}

\subsection{Materials}

The iron mine tailings collected from a hematite ore mine in Jiayuguan City, China, containing $32.82 \% \mathrm{Fe}$ and $38.66 \% \mathrm{SiO}_{2}$, were tested for flocculation and sedimentation studies. The sample with an average particle size of $17.11 \mu \mathrm{m}$ displayed a bad kind of sedimentation capacity without flocculants, and the main iron mineral in the tailings was hematite. Moreover, the pure hematite sample $(98.13 \%$ $\mathrm{Fe}_{2} \mathrm{O}_{3}$, minus $30 \mu \mathrm{m}$ ) was used for the mechanism studies. Chemical compositions of materials used are given in Table 1 .

Table 1. Chemical compositions of material used.

\begin{tabular}{ccccccc}
\hline Sample & $\mathrm{Fe}_{\mathbf{2}} \mathrm{O}_{\mathbf{3}}(\mathbf{\%})$ & $\mathrm{SiO}_{\mathbf{2}}(\mathbf{\%})$ & $\mathrm{Al}_{\mathbf{2}} \mathrm{O}_{\mathbf{3}}(\mathbf{\%})$ & $\mathrm{CaO}(\%)$ & $\mathbf{M g O}(\%)$ & LOI (\%) \\
\hline Hematite ore slimes & 44.86 & 38.66 & 6.17 & 2.75 & 3.15 & 2.45 \\
Pure hematite & 98.13 & 0.68 & 0.48 & 0.06 & 0.05 & 0.47 \\
\hline
\end{tabular}

LOI = loss on ignition. 
$\operatorname{APAM}\left(\left(\mathrm{C}_{2} \mathrm{H}_{3} \mathrm{CONH}_{2}\right)_{n}\left(\mathrm{C}_{2} \mathrm{H}_{3} \mathrm{COONa}\right)_{\mathrm{m}}\right)$ with a 5 million molecular weight was prepared into a $1 \mathrm{~g} / \mathrm{L}$ solution as the flocculant for iron tailings slurry, and then a reagent of $100 \mathrm{mg} / \mathrm{L} \mathrm{Fe}^{3+}$ solution was prepared using $\mathrm{Fe}(\mathrm{III})$ salts $\left(\mathrm{FeCl}_{3} \cdot 6 \mathrm{H}_{2} \mathrm{O}\right)$. Reagents of $50 \mathrm{~g} / \mathrm{L} \mathrm{NaOH}$ and $\mathrm{HCl}$ solutions were prepared as the $\mathrm{pH}$ regulators.

\subsection{Methods}

\subsubsection{Flocculation and Sedimentation Tests}

The tailings slurry ( $20 \mathrm{~g} / \mathrm{L})$ using $2 \mathrm{mg} / \mathrm{L}$ APAM was conditioned for $1 \mathrm{~min}$ at the stirring speed of $350 \mathrm{rev} / \mathrm{min}$. After the flocculation, a certain concentration of $\mathrm{Fe}^{3+}$ was subsequently added into the suspension for conditioning for a certain time at a stirring speed of $350 \mathrm{rev} / \mathrm{min}$. The tailings pulp was finally introduced into a graduated cylinder for sedimentation tests.

\subsubsection{Flocs' Size Study}

The tailings slurry $(20 \mathrm{~g} / \mathrm{L})$ flocculated using $2 \mathrm{mg} / \mathrm{L}$ APAM was treated for certain time with the addition of $\mathrm{Fe}^{3+}$, and finally transferred into a smaller beaker for size measurements using a Mastersizer2000 analyzer (Malvern Corporation, Worcestershire, UK). It was worth noting that the stirring speed of the analyzer should be less than $1000 \mathrm{rev} / \mathrm{min}$ due to the unsteady or fragile agglomeration, and the ultrasonic function of the analyzer should be turned off, too.

\subsubsection{Zeta Potential Analysis}

Firstly, $30 \mathrm{mg}$ hematite (minus $5 \mu \mathrm{m}$ ) was cleaned in the deionized water via an ultrasonic cleaner for $5 \mathrm{~min}$. The suspension was subsequently conditioned in the presence of reagents (APAM and $\mathrm{Fe}^{3+}$ ) and stirred for a certain time for a $\mathrm{pH}$ adjustment using the $\mathrm{pH}$ regulators of $\mathrm{NaOH}$ and $\mathrm{HCl}$ solution. After the equilibrium of $\mathrm{pH}$, a supernatant of the suspension was obtained for zeta potential measurements using a Coulter Delsa-440SX zeta potential analyzer (Brookhaven Corporation, Long Island, NY, USA).

\subsubsection{Fourier Transform Infrared Spectroscopic (FTIR) Study}

Hematite (less than $2 \mu \mathrm{m}$ ) conditioned with APAM and hematite-APAM in the presence of $\mathrm{Fe}^{3+}$ solution was prepared first. The precipitates were dried at $50{ }^{\circ} \mathrm{C}$ and then the resultant samples were used for FTIR measurements using an IRAffinity-1 spectrometer (Shimadzu Corporation, Kyoto, Japan). In addition, samples of APAM and APAM in the presence of $\mathrm{Fe}^{3+}$ solution were also measured using the transmission method.

\subsubsection{Scanning Electron Microscope (SEM) Imaging}

Samples of $2 \mathrm{~g}$ pure hematite in the size range of 20-30 $\mu \mathrm{m}$ were prepared first using the elutriation method, and then dispersed in $50 \mathrm{~cm}^{3}$ deionized water for $5 \mathrm{~min}$. Then suspensions of hematite coated with the APAM and hematite-APAM in the presence of $\mathrm{Fe}^{3+}$ were prepared. In addition, the $1 \mathrm{~g} / \mathrm{L}$ APAM solution and the APAM solution conditioned with $56 \mathrm{mg} / \mathrm{L} \mathrm{Fe}^{3+}$ were directly prepared. After conditioning, the dried samples with gold powder were prepared for SEM imaging using the Model JSM-6360LV (JEOL Corporation, Tokyo, Japan).

\section{Results and Discussion}

\subsection{Flocculation and Sedimentation Tests}

Figure 1 indicates that the settling rate of the slurry decreased rapidly after adding $20 \mathrm{mg} / \mathrm{L}$ $\mathrm{Fe}^{3+}$, and then the settling ability decreased slightly with the increased dosage of $\mathrm{Fe}^{3+}$ in the range of $20-56 \mathrm{mg} / \mathrm{L}$. However, it was a surprise in Figure 1 that the settling ability increased with the increase of $\mathrm{Fe}^{3+}$ in the range of $56-150 \mathrm{mg} / \mathrm{L}$, and the settling effect using $150 \mathrm{mg} / \mathrm{L} \mathrm{Fe}^{3+}$ was still worse than that without adding $\mathrm{Fe}^{3+}$. These demonstrated that a low concentration of $20-56 \mathrm{mg} / \mathrm{L} \mathrm{Fe}^{3+}$ could 
produce a positive effect on the regulating behavior in terms of the reduced settling ability, but a large concentration of 56-150 mg/ $\mathrm{L} \mathrm{Fe}^{3+}$ produced an adverse effect of regulating behavior due to the hetero-coagulation between $\mathrm{Fe}(\mathrm{OH})_{3}$ colloids and tailings [31]. Therefore, a moderate dosage of $\mathrm{Fe}^{3+}$ could be suggested as $56 \mathrm{mg} / \mathrm{L}$ here. Figure 2 shows that the settling rate of the slurry using $\mathrm{Fe}^{3+}$ decreased with the increase of regulating time; however, the regulating efficiency was low during the first $1 \mathrm{~min}$. These suggested the interaction kinetics between $\mathrm{Fe}^{3+}$ and the flocs appeared slow at first and then fast, which might be attributed to the $\mathrm{Fe}^{3+}$ dispersion in the slurry and collision efficiency between the active species and the polymer molecules on the flocs. Figure 3 indicates that a high regulating effect was produced in the presence of $\mathrm{Fe}^{3+}$ at $\mathrm{pH}$ 6-7, and then decreased with the increase of slurry $\mathrm{pH}$. The pulp $\mathrm{pH}$ had a critical influence on the chemical species' distributions of Fe(III) [32]. Concentration of $\mathrm{Fe}^{3+}$ and related hydroxyl complex ions $\left(\mathrm{Fe}(\mathrm{OH})^{2+}\right.$ and $\left.\mathrm{Fe}(\mathrm{OH})_{2}{ }^{+}\right)$decreased with the increase of pulp $\mathrm{pH}$, resulting in a decreasing regulating degree. In this study the addition of $56 \mathrm{mg} / \mathrm{L} \mathrm{Fe}^{3+}$ could produce a bad flocculation-sedimentation effect with strong regulating behavior for the flocs at $\mathrm{pH}$ 6.4. It can be inferred from Figure 4 that the slurry only adding $\mathrm{Fe}^{3+}$ produced $^{3}$ a better settling effect than that without flocculants (APAM and $\mathrm{Fe}^{3+}$ ) at $\mathrm{pH}$ 6.4, and the increased $\mathrm{pH}$ (alkaline slurry) was not beneficial to the settling effect might due to the higher slurry dispersion and the precipitate of coagulant. However, it was a surprise that the settling effect of the slurry using APAM first and then $\mathrm{Fe}^{3+}$ was worse than that using $\mathrm{Fe}^{3+}$ first and then APAM, indicating that the adding order of reagents was critical to the settling effect. Therefore, the method using APAM first and then $\mathrm{Fe}^{3+}$ at $\mathrm{pH}$ 6-7 could produce a good regulating effect on the slurry.

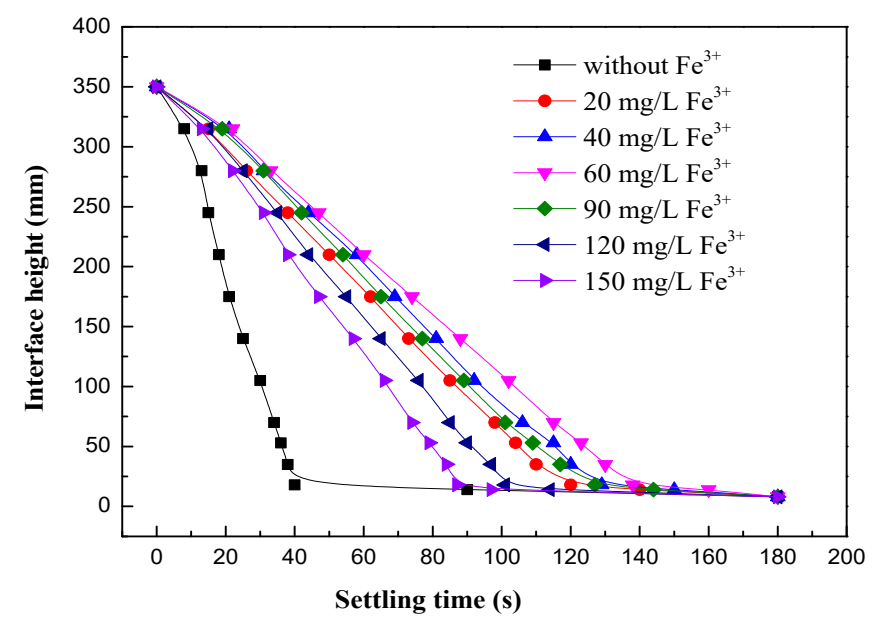

Figure 1. Effect of $\mathrm{Fe}^{3+}$ dosage on the sedimentation (APAM: $2 \mathrm{mg} / \mathrm{L}, \mathrm{pH}: 6-7$, regulating time: $5 \mathrm{~min}$ ).

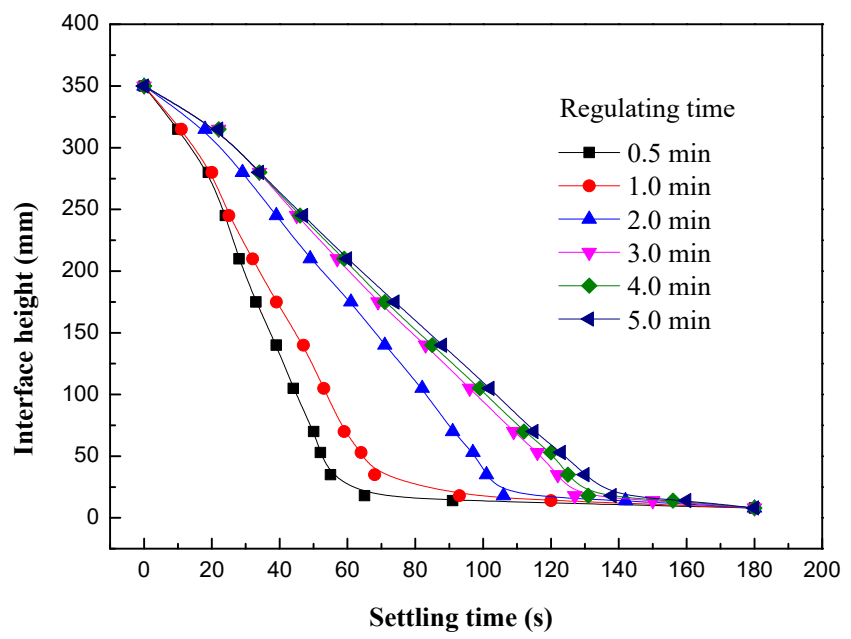

Figure 2. Effect of $\mathrm{Fe}^{3+}$ regulating time on the sedimentation (APAM: $2 \mathrm{mg} / \mathrm{L}, \mathrm{pH}: 6.4, \mathrm{Fe}^{3+}: 56 \mathrm{mg} / \mathrm{L}$ ). 


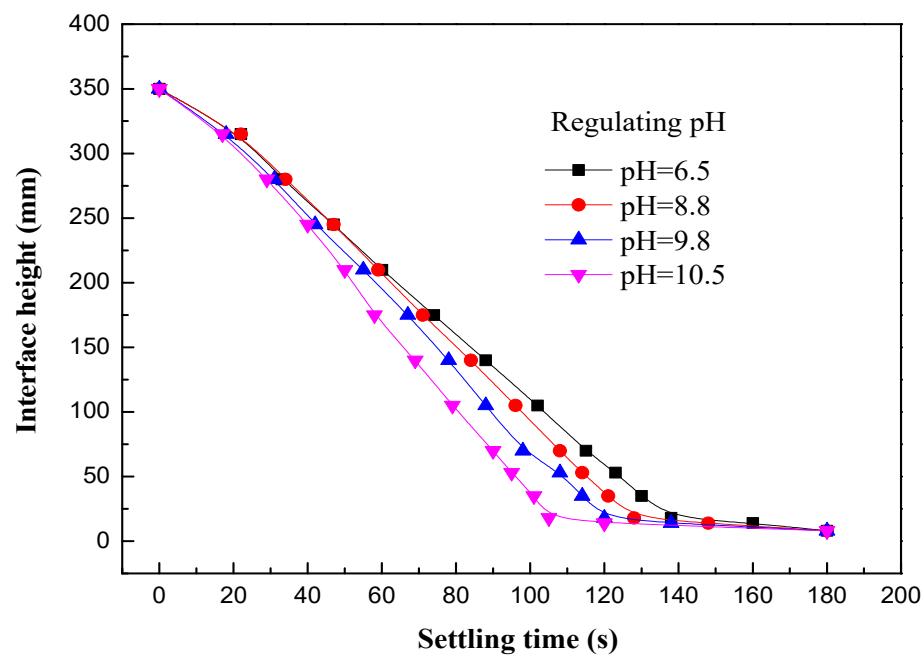

Figure 3. Effect of $\mathrm{pH}$ on the sedimentation (APAM: $2 \mathrm{mg} / \mathrm{L}$, regulating time: $5 \mathrm{~min}, \mathrm{Fe}^{3+}: 56 \mathrm{mg} / \mathrm{L}$ ).

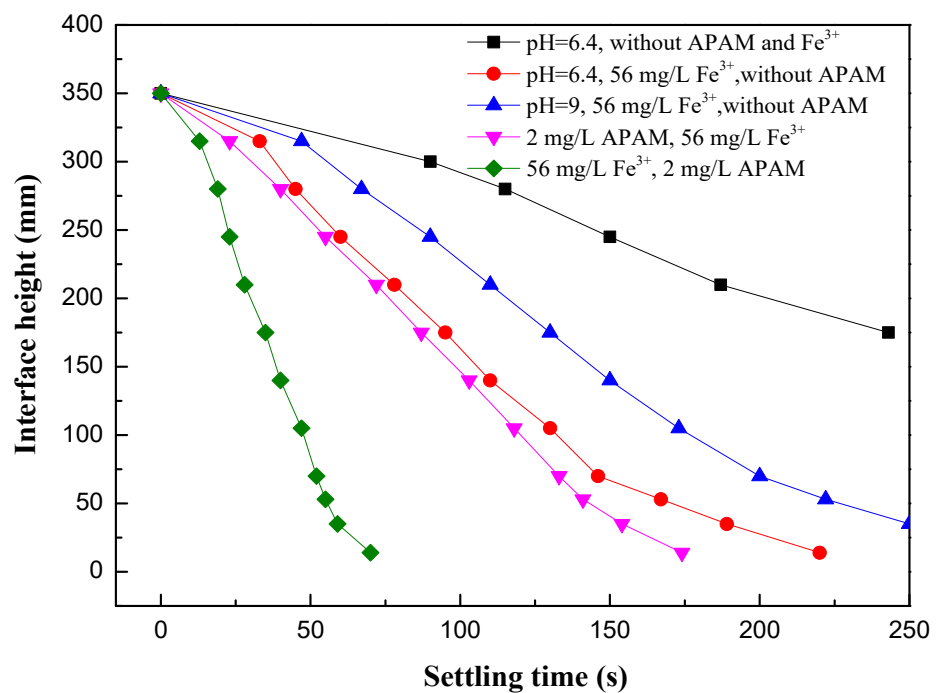

Figure 4. Effect of $\mathrm{Fe}^{3+}$ and adding order of reagents on the sedimentation (regulating time: 5 min).

Based on the flocculation-sedimentation tests, it was concluded that a recommended addition of $56 \mathrm{mg} / \mathrm{L} \mathrm{Fe}^{3+}$ at neutral $\mathrm{pH}$ produced a good regulating effect in terms of a surprisingly bad flocculation effect; this regulating behavior might be beneficial to weaken or reduce the adverse effect of the flocs and the residual APAM in the slurry on the following flotation process, such as the flotation selectivity.

\subsection{Flocs' Size Analysis}

Table 2 presents the flocs' size change while adding certain $\mathrm{Fe}^{3+}$ solution under different conditions. It can be inferred that the regulating ability of $\mathrm{Fe}^{3+}$ was related to the change of floc size, which increased with the decrease of size. As shown in Table 2, the flocs' size decreased with the increasing $\mathrm{Fe}^{3+}$ dosage first and then increased with the further increase of $\mathrm{Fe}^{3+}$; the flocs' size decreased by $39.25 \%$ with the increase of regulating time in $5 \mathrm{~min}$, but the size was only decreased by $9.66 \%$ (from 41.28 to $37.29 \mu \mathrm{m}$,) during the first $1 \mathrm{~min}$; and the flocs' size decreased with the increase of slurry $\mathrm{pH}$ and exhibited a fine size at neutral $\mathrm{pH}$. The flocs' size change agreed well with the sedimentation effects, i.e. the regulating behavior could be explained as the "damage" to the flocs. 
Table 2. Effect of $\mathrm{Fe}^{3+}$ on the flocs' size based on its regulating behavior.

\begin{tabular}{|c|c|c|c|c|c|}
\hline Iron Tailings Slurry & $\mathrm{d}(0.1)(\mu \mathrm{m})$ & $\mathrm{d}(0.5)(\mu \mathrm{m})$ & $\mathrm{d}(0.9)(\mu \mathrm{m})$ & Average Size $(\mu \mathrm{m})$ & Specific Area $\left(\mathrm{m}^{2} / \mathrm{g}\right)$ \\
\hline Tailings slurry & 4.672 & 15.324 & 32.083 & 17.114 & 0.172 \\
\hline Slurry with $2 \mathrm{mg} / \mathrm{L}$ PAM & 9.618 & 28.266 & 69.768 & 41.277 & 0.087 \\
\hline $2 \mathrm{mg} / \mathrm{L} \mathrm{PAM}$ and $20 \mathrm{mg} / \mathrm{L} \mathrm{Fe}^{3+}$ & 6.456 & 22.064 & 60.086 & 32.491 & 0.117 \\
\hline $2 \mathrm{mg} / \mathrm{L}$ PAM and $40 \mathrm{mg} / \mathrm{L} \mathrm{Fe}^{3+}$ & 5.574 & 18.437 & 50.085 & 28.023 & 0.136 \\
\hline $2 \mathrm{mg} / \mathrm{L} \mathrm{PAM}$ and $56 \mathrm{mg} / \mathrm{L} \mathrm{Fe}^{3+}$ & 5.298 & 17.901 & 48.675 & 25.077 & 0.141 \\
\hline $2 \mathrm{mg} / \mathrm{L}$ PAM and $90 \mathrm{mg} / \mathrm{L} \mathrm{Fe}^{3+}$ & 5.557 & 18.341 & 49.487 & 27.620 & 0.139 \\
\hline $2 \mathrm{mg} / \mathrm{L} \mathrm{PAM}$ and $120 \mathrm{mg} / \mathrm{L} \mathrm{Fe}^{3+}$ & 5.784 & 20.405 & 55.080 & 29.288 & 0.125 \\
\hline $2 \mathrm{mg} / \mathrm{L} \mathrm{PAM}$ and $150 \mathrm{mg} / \mathrm{L} \mathrm{Fe}^{3+}$ & 7.596 & 23.305 & 58.971 & 33.044 & 0.104 \\
\hline $2 \mathrm{mg} / \mathrm{L} \mathrm{PAM}, 56 \mathrm{mg} / \mathrm{L} \mathrm{Fe}^{3+}, \mathrm{t}=0.5 \mathrm{~min}$ & 7.147 & 23.854 & 80.920 & 39.170 & 0.107 \\
\hline $2 \mathrm{mg} / \mathrm{L} \mathrm{PAM}, 56 \mathrm{mg} / \mathrm{L} \mathrm{Fe}^{3+}, \mathrm{t}=1.0 \mathrm{~min}$ & 6.649 & 22.272 & 75.358 & 37.291 & 0.114 \\
\hline $2 \mathrm{mg} / \mathrm{L} \mathrm{PAM}, 56 \mathrm{mg} / \mathrm{L} \mathrm{Fe}^{3+}, \mathrm{t}=2.0 \mathrm{~min}$ & 5.971 & 20.262 & 60.075 & 31.813 & 0.126 \\
\hline $2 \mathrm{mg} / \mathrm{L} \mathrm{PAM}, 56 \mathrm{mg} / \mathrm{L} \mathrm{Fe}^{3+}, \mathrm{t}=3.0 \mathrm{~min}$ & 5.722 & 18.725 & 56.098 & 29.847 & 0.132 \\
\hline $2 \mathrm{mg} / \mathrm{L} \mathrm{PAM}, 56 \mathrm{mg} / \mathrm{L} \mathrm{Fe}^{3+}, \mathrm{t}=4.0 \mathrm{~min}$ & 5.347 & 17.915 & 51.215 & 26.404 & 0.140 \\
\hline $2 \mathrm{mg} / \mathrm{L} \mathrm{PAM}, 56 \mathrm{mg} / \mathrm{L} \mathrm{Fe}^{3+}, \mathrm{t}=5.0 \mathrm{~min}$ & 5.298 & 17.901 & 48.675 & 25.077 & 0.141 \\
\hline $2 \mathrm{mg} / \mathrm{L}$ PAM, $56 \mathrm{mg} / \mathrm{L} \mathrm{Fe}^{3+}$, pH 6.5 & 5.298 & 17.901 & 48.675 & 25.077 & 0.141 \\
\hline $2 \mathrm{mg} / \mathrm{L}$ PAM,56 mg/L Fe ${ }^{3+}, \mathrm{pH} 8.8$ & 6.211 & 20.330 & 51.681 & 27.414 & 0.124 \\
\hline $2 \mathrm{mg} / \mathrm{L} \mathrm{PAM}, 56 \mathrm{mg} / \mathrm{L} \mathrm{Fe}^{3+}, \mathrm{pH} 9.8$ & 6.960 & 22.421 & 55.813 & 31.361 & 0.112 \\
\hline $2 \mathrm{mg} / \mathrm{L}$ PAM, $56 \mathrm{mg} / \mathrm{L} \mathrm{Fe}^{3+}, \mathrm{pH} 10.5$ & 7.689 & 24.194 & 61.992 & 33.665 & 0.104 \\
\hline $2 \mathrm{mg} / \mathrm{L}$ PAM, $56 \mathrm{mg} / \mathrm{L} \mathrm{Fe}^{3+}, \mathrm{pH} 11.2$ & 7.905 & 24.455 & 62.396 & 34.066 & 0.102 \\
\hline
\end{tabular}

$\mathrm{t}=$ regulating time.

\subsection{Zeta Potential and Solution Chemistry Studies}

It was demonstrated that the pulp $\mathrm{pH}$ had an important effect on the regulating behavior, therefore, zeta potential and solution chemistry studies of hematite-APAM in the presence of $\mathrm{Fe}^{3+}$ were investigated, as given in Figures 5 and 6.

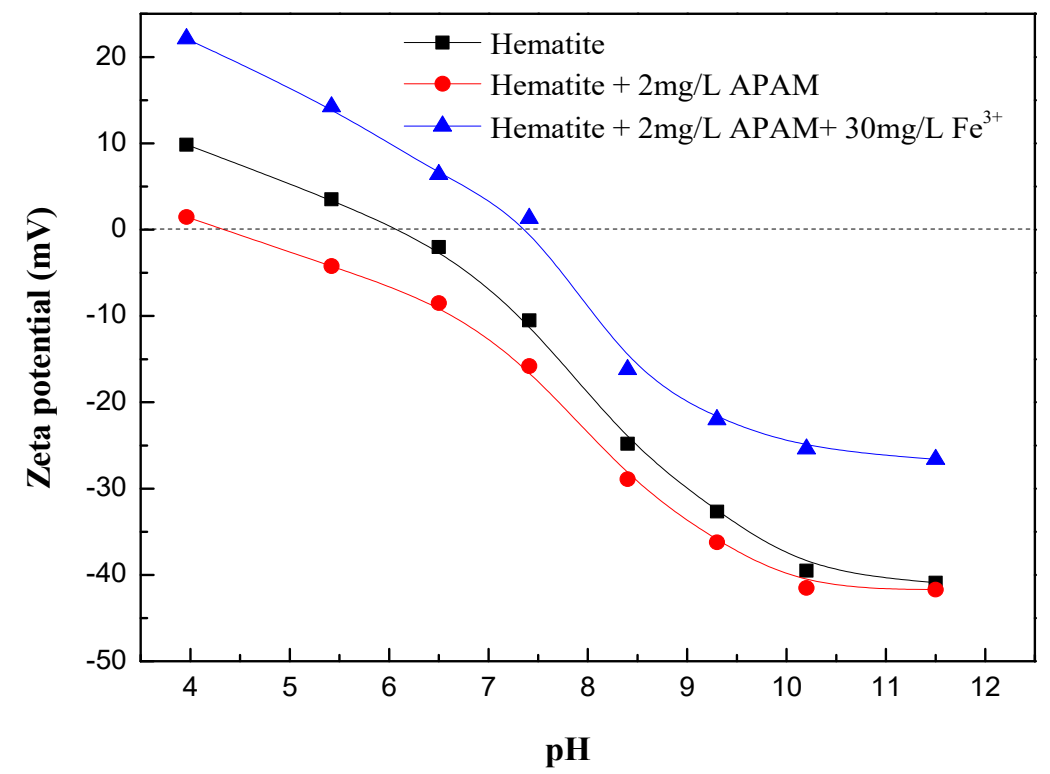

Figure 5. Effect of $\mathrm{pH}$ on the zeta potentials of hematite-APAM in the presence of $\mathrm{Fe}^{3+}$. 


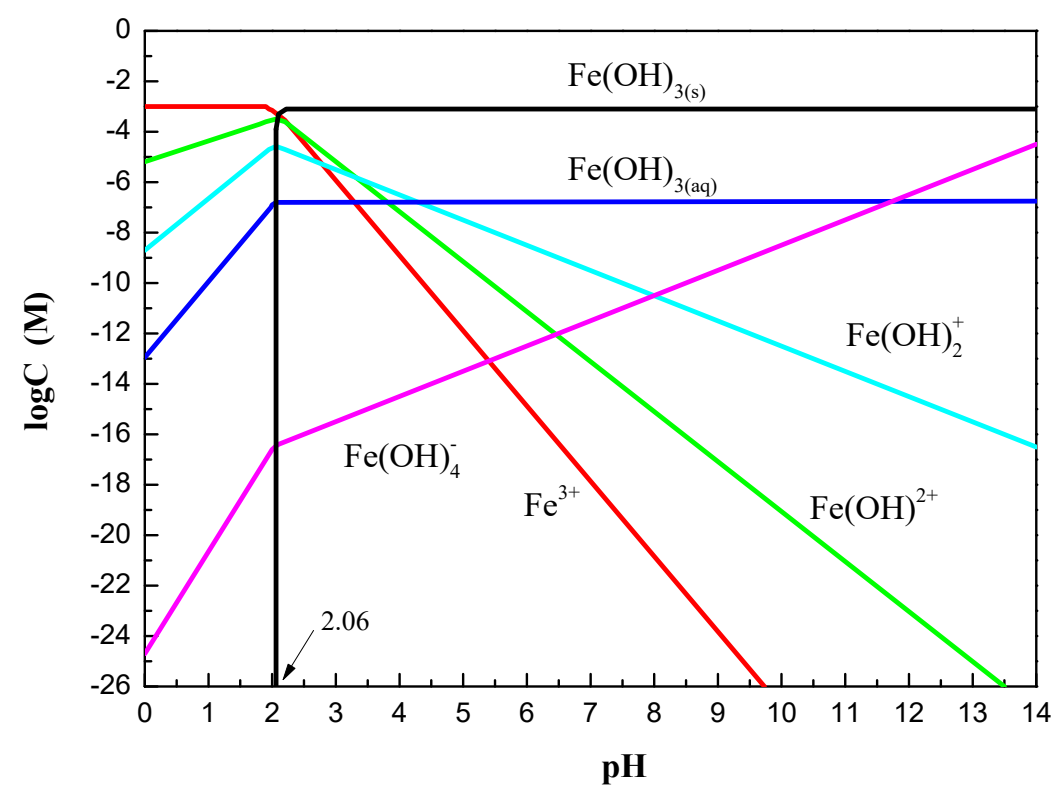

Figure 6. Species distribution diagram of $\mathrm{Fe}^{3+}$ as a function of $\mathrm{pH}\left(\mathrm{C}_{\mathrm{T}}: 1 \times 10^{-3} \mathrm{~mol} / \mathrm{L}\right)$.

As shown in Figure 5, the iso-electric point of hematite has a negative shift after adding $2 \mathrm{mg} / \mathrm{L}$ of APAM, indicating that the APAM contained a large number of polar groups, such as acyl and carboxyl groups, which adsorbed onto the hematite. The hematite flocculated by APAM has a positive potential below pH 7 while adding $\mathrm{Fe}^{3+}$ and the absolute values of hematite potential were raised between pH 4 and 12, suggesting that the electrostatic adsorption and complexation happened between $\mathrm{Fe}^{3+}$ (related active species) and the polar groups of APAM. Furthermore, competitive adsorption between the $\mathrm{Fe}^{3+}$ ions and APAM molecules on the hematite also had an important influence on the potential.

Figure 6 presents the $\log \mathrm{C}-\mathrm{pH}$ diagram of $\mathrm{Fe}^{3+}$. The species of $\mathrm{Fe}(\mathrm{OH})_{3(\mathrm{~s})}$ and $\mathrm{Fe}(\mathrm{OH})_{4}{ }^{-}$display a high concentration at neutral and alkali $\mathrm{pH}$. The main species of $\mathrm{Fe}^{3+}, \mathrm{Fe}(\mathrm{OH})^{2+}$, and $\mathrm{Fe}(\mathrm{OH})_{2}{ }^{+}$ are widely distributed at $\mathrm{pH} 0-10 . \mathrm{Fe}^{3+}$ and its hydroxyl complex ions in the solution at $\mathrm{pH} 7$ were calculated to be $1 \times 10^{-18} \mathrm{~mol} / \mathrm{L} \mathrm{Fe}^{3+}, 1 \times 10^{-13} \mathrm{~mol} / \mathrm{L} \mathrm{Fe}(\mathrm{OH})^{2+}$, and $1 \times 10^{-9} \mathrm{~mol} / \mathrm{L}$ $\mathrm{Fe}(\mathrm{OH})_{2}{ }^{+}$, respectively, but the concentration of them were "small", which mainly interacted with the APAM. Studies reported that the interaction between them decreased the charge density on the APAM molecules, resulting in great contractility of the PAM molecules [28,29]. Therefore, the APAM molecules adsorbed on the hematite particles might be affected via adding certain Fe(III) salts.

\subsection{FTIR Spectra of Hematite-APAM Treated with $\mathrm{Fe}^{3+}$}

Figure 7 presents the FTIR spectra of APAM and hematite-APAM conditioned with $\mathrm{Fe}^{3+}$. As shown in the spectrum of APAM that the adsorption around $3200 \mathrm{~cm}^{-1}$ was related to the $-\mathrm{NH}_{2}$ (associative) stretching vibration, and the band at $1662 \mathrm{~cm}^{-1}$ was attributed to the carbonyl group corresponding to the $\mathrm{C}=\mathrm{O}$ stretching vibration of the amide group, and then the $-\mathrm{COO}$ adsorption characteristic was also observed around $1540 \mathrm{~cm}^{-1}$. The peak at $3350-3400 \mathrm{~cm}^{-1}$ was the $-\mathrm{NH}_{2}$ (free) stretching vibration. Compared to the spectrum of APAM- $\mathrm{Fe}^{3+}$, a small band at $1040 \mathrm{~cm}^{-1}$ referred to the external bending vibration peak of olefins produced by double bonds, which could be called the characteristic peak of acrylamide monomer, suggesting that a type of weak degradation of APAM took place in the presence of $\mathrm{Fe}^{3+}$. As shown in the FTIR spectra of hematite-APAM, the -COO adsorption at $1540 \mathrm{~cm}^{-1}$ and $\mathrm{C}-\mathrm{N}$ stretching vibration nearing $1400 \mathrm{~cm}^{-1}$ were observed, demonstrating the chemisorption and hydrogen bonding adsorption of APAM onto hematite. Then it can be inferred from the hematite-APAM in the presence of the $\mathrm{Fe}^{3+}$, the intensities of $\mathrm{C}-\mathrm{N}$ stretching vibration band at $1400 \mathrm{~cm}^{-1}$, and the $\mathrm{C}=\mathrm{O}$ stretching vibration band around $1662 \mathrm{~cm}^{-1}$ were improved, suggesting the adsorption of APAM molecules on hematite was intensified due to small acrylamide molecules by degradation. 


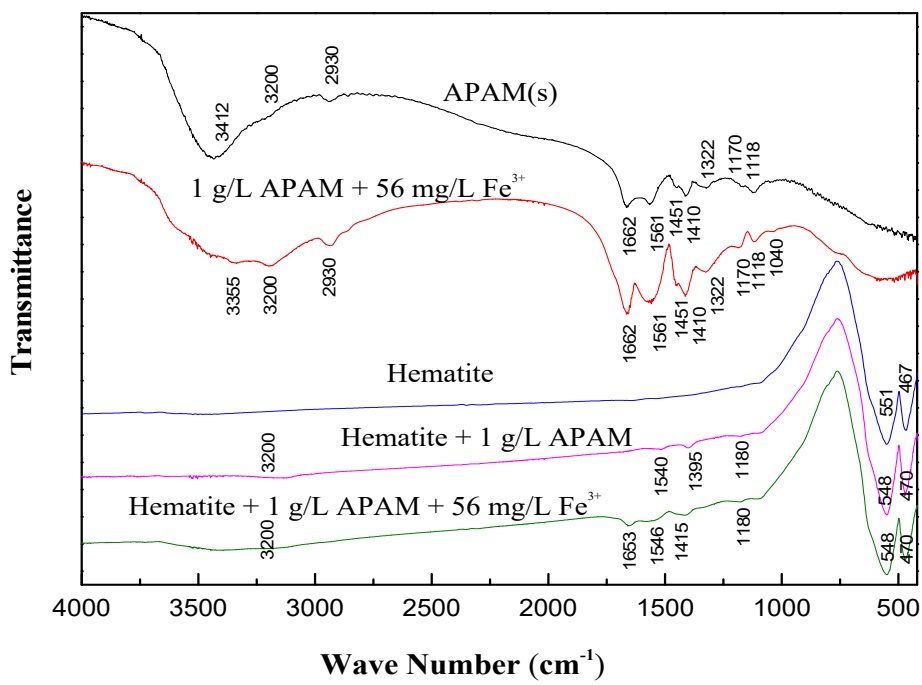

Figure 7. FTIR spectra of APAM and hematite-APAM in the presence of $\mathrm{Fe}^{3+}$.

\subsection{Surface Characterization (SEM imaging) and Proposed Model of APAM in the Presence of Fe ${ }^{3+}$}

Figure $8 \mathrm{a}$ shows the crystal of APAM solution in the natural state. It can be seen from the crystal that the APAM presents large molecules, forming into a type of spatial network structure. Then Figure $8 \mathrm{~b}$ shows the crystal of APAM in the presence of $\mathrm{Fe}^{3+}$, which appears like a type of colloidal flocs releasing "bound water" by making the polymer curl. Therefore, the APAM in terms of colloidal flocs adsorbed on the hematite might be cleaned via mechanical stirring action in the slurry, which was confirmed in Figure 8d. Figure 8c presents the hematite conditioned with the APAM solution, it can be observed that there are large amounts of APAM coated on the hematite particles. Figure $8 \mathrm{~d}$ reveals the adsorption characteristics of APAM on the hematite particles after conditioning with $\mathrm{Fe}^{3+}$, and the surface of hematite was cleaner and the APAM adsorption amount was smaller than that in Figure 8c. These characteristics agree well with the APAM desorption from hematite in the presence of $\mathrm{Fe}^{3+}$.
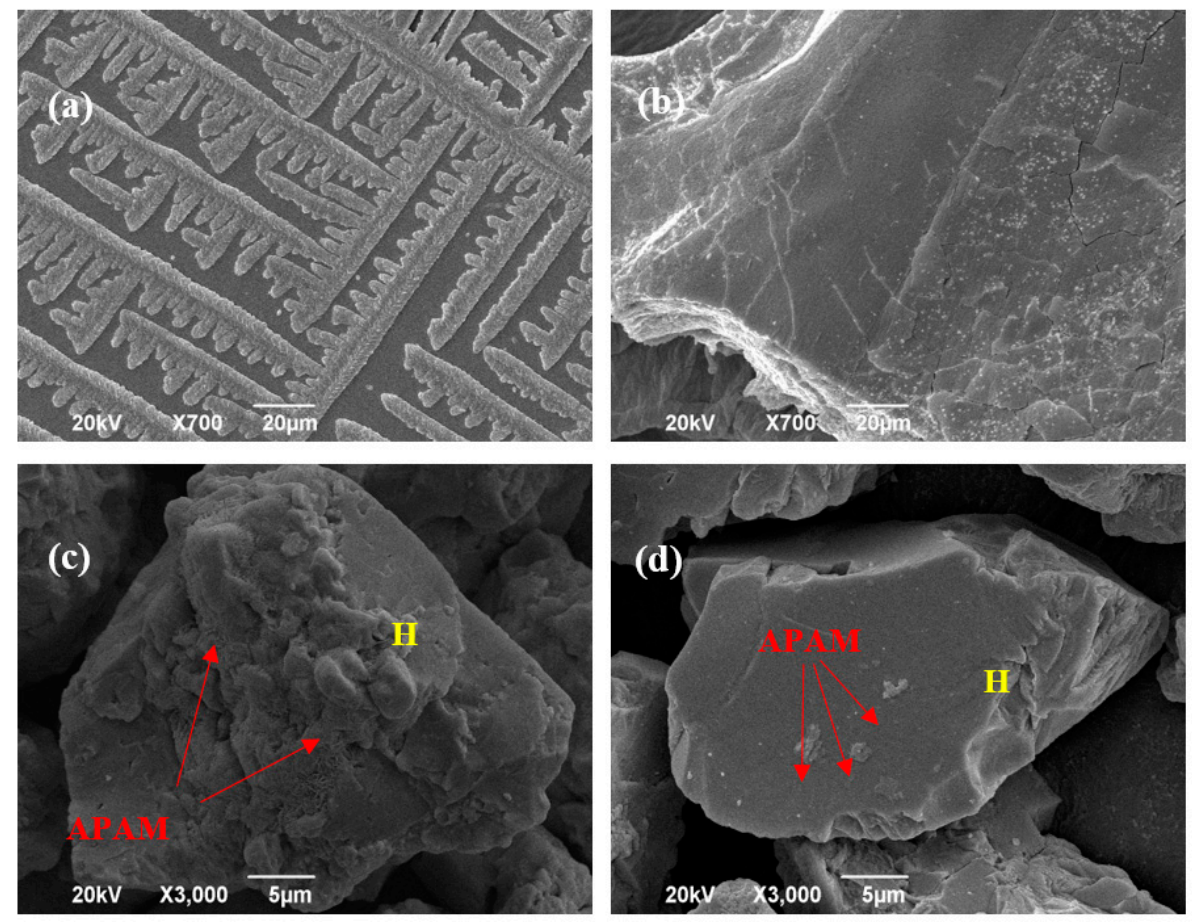

Figure 8. SEM images of (a) APAM, (b) APAM treated with $\mathrm{Fe}^{3+}$, (c) hematite treated with APAM, and $(\mathbf{d})$ hematite coated with APAM in the presence of $\mathrm{Fe}^{3+}$. H: hematite $(20-30 \mu \mathrm{m})$. 
Based on the zeta potential analysis and SEM imaging, a proposed model of the APAM in the presence of $\mathrm{Fe}^{3+}$ is illustrated in Figure 9. In the simplified model, a small concentration of free $\mathrm{Fe}^{3+}$ (as calculated in Figure 6 at $\mathrm{pH}$ 7: $1 \times 10^{-18} \mathrm{~mol} / \mathrm{L}$ ) only played an auxiliary effect on the electrostatic adsorption, which was mainly produced by the complex ions (such as $1 \times 10^{-13} \mathrm{~mol} / \mathrm{L} \mathrm{Fe}(\mathrm{OH})^{2+}$ and $\left.1 \times 10^{-9} \mathrm{~mol} / \mathrm{L} \mathrm{Fe}(\mathrm{OH})_{2}{ }^{+}\right)$. In addition, the hydrogen bonding adsorption $[33,34]$ of $\mathrm{Fe}(\mathrm{OH})^{2+}$ and $\mathrm{Fe}(\mathrm{OH})_{2}{ }^{+}$on the polymer molecular chain should also be considered due to a large number of polar groups in the polymer molecules. This model only proposes that the interaction between active species and the APAM molecular chain lies in the electrostatic adsorption and complexation in the electric double layer of the polymer molecular chain, suggesting that this interaction could decrease the negative charge density and then affect the stretch degree of the APAM molecules (confirmed in Figure 8a,b).

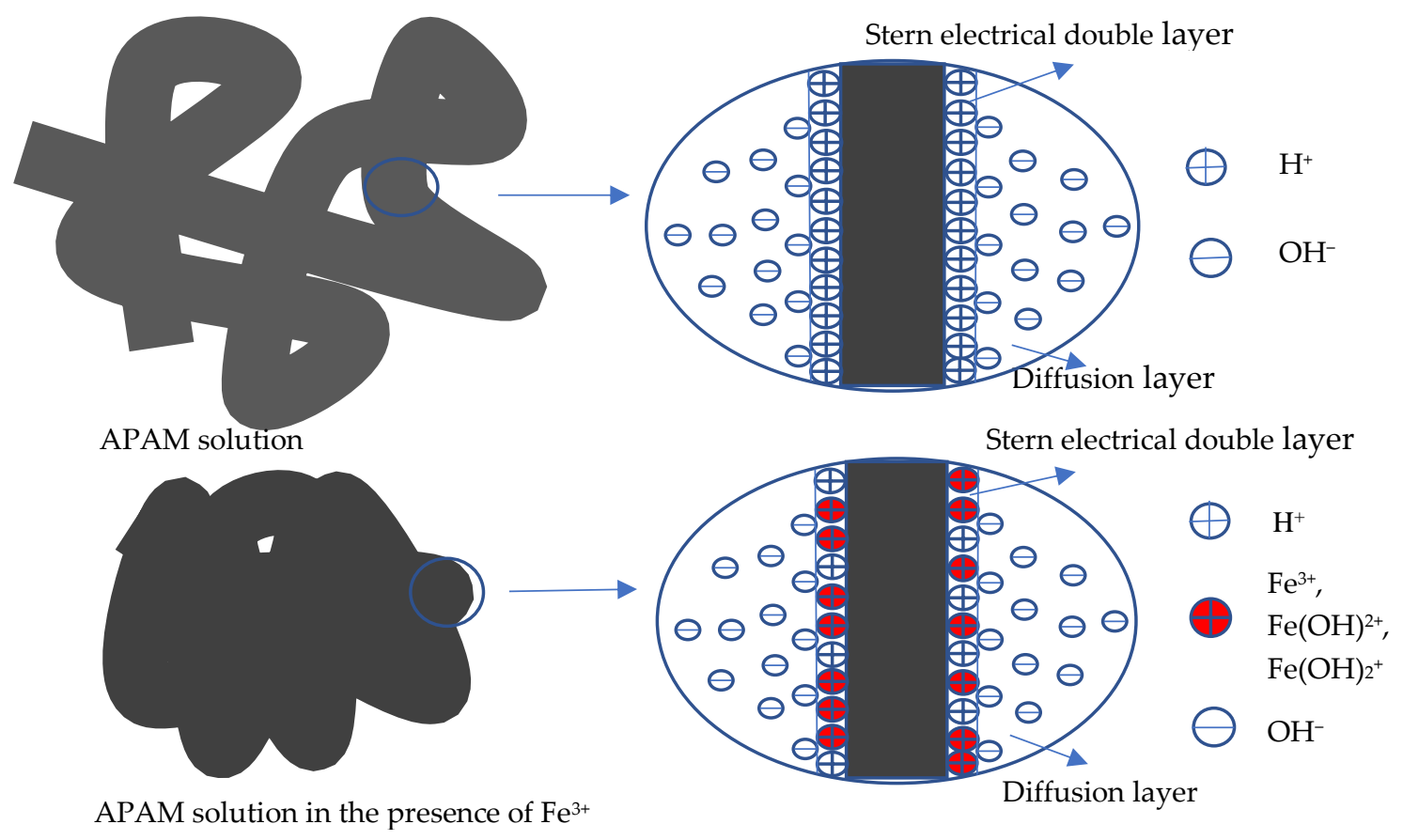

Figure 9. Proposed model of the APAM molecular chain in the presence of regulator $\mathrm{Fe}^{3+}$ at $\mathrm{pH} 7$.

\section{Summary}

There were three critical factors investigated in the flocculation-sedimentation tests, including the addition of $\mathrm{Fe}^{3+}$, slurry $\mathrm{pH}$, and the regulating time. The use of $\mathrm{Fe}^{3+}$ produced a positive regulating effect on the sedimentation under a certain dosage of $\mathrm{Fe}^{3+}$ reagent, but the high addition of $\mathrm{Fe}^{3+}$ led to a negative regulating effect. The high regulating ability using $\mathrm{Fe}^{3+}$ reagent was obtained at a neutral $\mathrm{pH}$, and the increase of slurry $\mathrm{pH}$ was not beneficial to the regulating effect. The regulating ability was low during the first $1 \mathrm{~min}$, but increased rapidly in the following $2 \mathrm{~min}$. In addition, the adding sequence of the APAM and $\mathrm{Fe}^{3+}$ affected the regulating ability, which showed a bad result while using $\mathrm{Fe}^{3+}$ first and then APAM. The regulating ability of $\mathrm{Fe}^{3+}$ agreed well with the floc size change, which increased with the decrease of flocs' size. So, the process using a certain concentration of $\mathrm{Fe}^{3+}$ at neutral $\mathrm{pH}$ could be recommended as a method to treat the wastewater containing APAM or the tailings flocculated by APAM.

Behind the high regulating ability of $\mathrm{Fe}^{3+}$, there were two main reasons: the desorption of the APAM and the weak degradation of APAM. The introduction of $\mathrm{Fe}^{3+}$ into the slurry produced related hydroxyl complex ions for electrostatic adsorption, complexation, and hydrogen bonding adsorption, which could decrease the charge density of the APAM molecules and then make the polymer chain curl more easily in terms of colloidal flocs, the colloid flocs of APAM were cleaned via stirring action, 
and this process could be called "desorption". The weak degradation of APAM took place in the presence of $\mathrm{Fe}^{3+}$, and the degradation could reduce the flocculating ability of APAM.

SEM studies confirmed that the network structure of APAM molecules treated with $\mathrm{Fe}^{3+}$ collapsed, and then the APAM adsorption amount on hematite was significantly reduced. A proposed model of the APAM molecular chain in the presence of $\mathrm{Fe}^{3+}$ was presented. It was noticed that the active species of the regulator ( $\mathrm{Fe}^{3+}$ solution in the slurry) were mainly its hydroxyl complex ions including $\mathrm{Fe}(\mathrm{OH})^{2+}$ and $\mathrm{Fe}(\mathrm{OH})_{2}{ }^{+}$.

Author Contributions: X.W. and T.Y. conceived and designed the ideas; T.Y., X.C., and T.L. performed the experiments; T.Y. and X.C. analyzed the data; X.W. and T.Y. contributed reagents/materials/analysis tools; T.Y. and X.W. wrote the paper.

Funding: This research was funded by [the National Natural Science Foundation of China] grant number [51274256].

Acknowledgments: The authors would like to acknowledge the financial support from the National Natural Science Foundation of China (No. 51274256) and the Key Laboratory of Hunan Province for Clean and Efficient Utilization of Strategic Calcium-containing Mineral Resources (No. 2018TP1002).

Conflicts of Interest: The authors declare no conflict of interest.

\section{References}

1. Ma, J.; Fu, K.; Jiang, L.; Ding, L.; Guan, Q.; Zhang, S.; Zhang, H.; Shi, J.; Fu, X. Flocculation performance of cationic polyacrylamide with high cationic degree in humic acid synthetic water treatment and effect of kaolin particles. Sep. Purif. Technol. 2017, 181, 201-212. [CrossRef]

2. Ariffin, A.; Razali, M.A.A.; Ahmad, Z. PolyDADMAC and polyacrylamide as a hybrid flocculation system in the treatment of pulp and paper mills waste water. Chem. Eng. J. 2012, 179, 107-111. [CrossRef]

3. Kutsevol, N.; Naumenko, A.; Chumachenko, V.; Balega, A.; Bulavin, L. Flocculative ability of uncharged and hydrolyzed graft and linear polyacrylamides. J. Mol. Liq. 2017, 227, 26-30. [CrossRef]

4. Wu, X.; Yue, T.; Dai, L. Magnetic seeding sedimentation (MSS) of coal slimes. IOP Conf. Ser Earth Environ. Sci. 2017, 52, 012003. [CrossRef]

5. Ng, W.S.; Sonsie, R.; Forbes, E.; Franks, G.V. Flocculation/Flotation of hematite fines with anionic temperature-responsive polymer acting as a selective flocculant and collector. Miner. Eng. 2015, 77, 64-71. [CrossRef]

6. Dwari, R.K.; Angadi, S.I.; Tripathy, S.K. Studies on flocculation characteristics of chromite's ore process tailing: Effect of flocculants ionicity and molecular mass. Colloids Surf. A. Physicochem. Eng. Asp. 2018, 537, 467-477. [CrossRef]

7. Yue, T.; Wu, X.; Dai, L. Effect of magnetic seeding agglomeration on flotation of fine minerals. J. Cent. South Univ. 2018, in press.

8. Wu, X.; Yue, T.; Dai, L. Magnetic seeding flotation of fine minerals. In Proceedings of the 28th International Conference of Mineral Processing (IMPC), Quebec, QC, Canada, 11-15 September 2016.

9. Zhang, X.; Ji, W.; Kang, Z.; Wang., J.; Yu, J.; Hou, B.; Han, H. Research progress in degradation of polyacrylamide. J. Environ. Prot. Oil Gas Fields 2008, 18, 41-45. (In Chinese)

10. Levitt, D.B.; Pope, G.A.; Jouenne, S. Chemical degradation of polyacrylamide polymers under alkaline conditions. SPE Reserv. Eval. Eng. 2011, 14, 281-286.

11. Castro, S.; Laskowski, J.S. Depressing effect of flocculants on molybdenite flotation. Miner. Eng. 2015, 74, 13-19. [CrossRef]

12. Chang, Z.; Feng, Q.; Ou, L. Study on the impact of flocculants in backwater on bauxite flotation. Nonferrous Met. Miner. Process. Sect. 2014, 6, 88-91. (In Chinese)

13. Pradip; Kulkarni, R.A.; Gundiah, S.; Moudgil, B.M. Selective flocculation of kaolinite from mixtures with tribasic calcium phosphate using hydrolyzed polyacrylamides. Int. J. Miner. Process. 1991, 32, 259-270. [CrossRef]

14. Yen, H.Y.; Yang, M.H. The ultrasonic degradation of polyacrylamide solution. Polym. Test. 2013, 22, 129-131. [CrossRef] 
15. Kay-Shoemake, J.L.; Watwood, M.E.; Lentz, R.D.; Sojka, R.E. Polyacrylamide as an organic nitrogen source for soil microorganisms with potential effects on inorganic soil nitrogen in agricultural soil. Soil Biol. Biochem. 1998, 30, 1045-1052. [CrossRef]

16. Vilcu, R.; Olteanu, M.; Mândru, I. Thermal behaviour of some mixture of collagen hydrolysates with vinylic polymers. Eur. Polym. J. 1985, 21, 81-83. [CrossRef]

17. Seright, R.S.; Campbell, A.; Mozley, P.; Han, P. Stability of partially hydrolyzed polyacrylamides at elevated temperatures in the absence of divalent cations. SPE J. 2010, 15, 341-348. [CrossRef]

18. Caulfield, M.J.; Hao, X.; Qiao, G.G.; Solomon, D.H. Degradation on polyacrylamides Part I: Linear polyacrylamide. Polymer 2003, 44, 1331-1337. [CrossRef]

19. Caulfield, M.J.; Hao, X.; Qiao, G.G.; Solomon, D.H. Degradation on polyacrylamides Part II: Polyacrylamide gels. Polymer 2003, 44, 3817-3826. [CrossRef]

20. Vijayalakshmi, S.P.; Madras, G. Photocatalytic degradation of poly (ethylene oxide) and polyacrylamide. J. Appl. Polym. Sci. 2010, 100, 3997-4003. [CrossRef]

21. Ramsden, D.K.; Mckay, K. Degradation of polyacrylamide in aqueous solution induced by chemically generated hydroxyl radicals: Part I-Fenton's reagent. Polym. Degrad. Stab. 1986, 14, 217-229. [CrossRef]

22. Ramsden, D.K.; Mckay, K. Degradation of polyacrylamide in aqueous solution induced by chemically generated hydroxyl radicals: Part II-Autoxidation of Fe ${ }^{2+}$. Polym. Degrad. Stab. 1986, 15, 15-31. [CrossRef]

23. Zhu, L.; Chang, Z.; Li, M.; Wang, E. Oxidative degradation of partially hydrolyzed polyacrylamide in aqueous solution i: Influence of temperature. Polym. Mater. Sci. Eng. 2000, 16, 113-116. (In Chinese)

24. Kłos, J.; Pakula, T. Monte Carlo simulations of a polyelectrolyte chain with added salt: Effect of temperature and salt valence. J. Chem. Phys. 2005, 123, 1-8. [CrossRef] [PubMed]

25. Kłos, J.; Pakula, T. Lattice Monte Carlo simulations of a charged polymer chain: Effect of valence and concentration of the added salt. J. Chem. Phys. 2005, 122, 1-7. [CrossRef] [PubMed]

26. Carrillo, J.M.Y.; Dobrtnin, A.V. Polyelectrolytes in salt solutions: Molecular dynamics simulations. Macromolecules 2011, 44, 5798-5816. [CrossRef]

27. Wang, J.; Zhao, F.L. Crosslinking mechanism of multivalent metal ions with polyacrylamide. J. China Univ. Pet. 1992, 16, 32-39. (In Chinese)

28. Li, M.R.; Liu, Z.; Song, X.W.; Ma, B.D.; Zhang, W. Effect of metal ions on the viscosity of polyacrylamide solution and the mechanism of viscosity degradation. J. Fuel Chem. Technol. 2012, 40, 43-47. (In Chinese) [CrossRef]

29. Jin, Y.X.; Wang, L.S.; Wang, T.; Zhang, X.; Yan, Y.G.; Liu, B. Experimental and theoretical study of the inorganic salts influence on the viscosity of partially hydrolyzed polyacrylamide in aqueous solution. J. China Univ. Pet. 2016, 40, 165-170. (In Chinese)

30. Liu, T.Y. Study on the Clarification of Ore Tailings Water by Magnetic Seeding Flocculation and Recycle of Magnetic Seeds. Master's Thesis, Central South University, Changsha, China, 2018.

31. Wills, B.A.; Napier-Munn, T.J. Wills' Mineral Processing Technology: An Introduction to the Practical Aspects of Ore Treatment and Mineral Recovery; Elsevier: Amsterdam, The Netherlands, 2006; pp. 378-379.

32. Peng, H.; Luo, W.; Wu, D.; Bie, X.; Shao, H.; Jiao, W.; Liu, Y. Study on the effect of Fe ${ }^{3+}$ on zircon flotation separation from cassiterite using sodium oleate as collector. Minerals 2017, 7, 108. [CrossRef]

33. Zhang, W.; Honaker, R.Q.; Groppo, J.G. Flotation of monazite in the presence of calcite part I: Calcium ion effects on the adsorption of hydroxamic acid. Miner. Eng. 2017, 100, 40-48. [CrossRef]

34. Zhang, W.; Honaker, R.Q. Flotation of monazite in the presence of calcite part II: Enhanced separation performance using sodium silicate and EDTA. Miner. Eng. 2018, 127, 318-328. [CrossRef]

(C) 2018 by the authors. Licensee MDPI, Basel, Switzerland. This article is an open access article distributed under the terms and conditions of the Creative Commons Attribution (CC BY) license (http://creativecommons.org/licenses/by/4.0/). 